\title{
What Is and What Might Be the Legacy of Felix Klein?
}

\author{
Hans-Georg Weigand, William McCallum, Marta Menghini, \\ Michael Neubrand, Gert Schubring and Renate Tobies
}

\begin{abstract}
Felix Klein always emphasised the great importance of teaching at the university, and he strongly promoted the modernisation of mathematics in the classrooms. The three books "Elementary Mathematics from a higher (advanced) standpoint" from the beginning of the last century gave and still give a model for university lectures especially for student teachers. The "Merano Syllabus" (1905), essentially initiated and influenced by Felix Klein, pleaded for an orientation of mathematics education at the concept of function, an increased emphasis on spatial geometry and an introduction of calculus in high schools. The Thematic Afternoon "The legacy of Felix Klein" will give an overview about the ideas of Felix Klein, it will highlight some developments in university teaching and school mathematics related to Felix Klein in the last century, and it will especially be asked for the meaning, the importance and the legacy of Klein's ideas nowadays and in the future in an international, worldwide context.
\end{abstract}

\footnotetext{
H.-G. Weigand ( $ه)$

University of Würzburg, Würzburg, Germany

e-mail: weigand@dmuw.de

W. McCallum

University of Arizona, Tucson, USA

e-mail:wmc@math.arizona.edu

M. Menghini

Sapienza University of Rome, Rome, Italy

e-mail: marta.menghini@uniroma1.it

M. Neubrand

University of Oldenburg, Oldenburg, Germany

e-mail: michael.neubrand@uni-oldenburg.de

G. Schubring

University of Bielefeld, Bielefeld, Germany

e-mail: gert.schubring@uni-bielefeld.de

R. Tobies

University of Jena, Jena, Germany

e-mail: renate.tobies@uni-jena.de
}

(C) The Author(s) 2017

G. Kaiser (ed.), Proceedings of the 13th International Congress on Mathematical

Education, ICME-13 Monographs, DOI 10.1007/978-3-319-62597-3_21 
When we talk about the legacy of Felix Klein, we are interested in the significance of Felix Klein's work for mathematics education, for our current theory and practice, and above all, for tomorrow's ideas concerning the teaching and learning of mathematics. We are interested in Felix Klein as a mathematician and as a mathematics teacher, but most of all we are interested in his ideas on teaching and learning mathematics, the problems he saw at university and at high school, and the solutions to these problems that he suggested. We are interested in these solutions because we recognise that we are nowadays confronted with similar or even the same problems as 100 years ago. Speaking about Felix Klein's legacy means hoping to get answers to some of the problems we are struggling with today. Speaking about Felix Klein's legacy today means giving answers to - at leastthree basic questions:

1. Which situations and which problems at the end of the 19th and the beginning of the 20th century can be seen in analogy to present situations?

2. How did Felix Klein react to these problems and which solutions did he suggest?

3. What do we know nowadays about the effect of the answers and solutions provided by Felix Klein 100 years ago?

Analogies between the situation 100 years ago and today can immediately be seen if we think about the current discussions concerning the goals and contents of teacher education at university, especially the problems of students, with the transition from high school to college or university and the transition back to high school. The problems with these transitions are expressed in Felix Klein's most famous statement, the "double discontinuity" from the introduction to Elementary mathematics from a higher standpoint, Volume I:

A mathematics freshman at the university is confronted with problems he had not been concerned with at school. After finishing university and becoming a teacher, he/she is expected to teach traditional elementary mathematics, which he was not confronted with at university. Therefore, he teaches mathematics the way he was taught some years ago and his university studies remain only a more or less pleasant memory which do not influence his teaching.

When we hear the lamentations of today's university professors about the decreasing abilities of first-year students, and when we note the negative views of young teachers about the effects of their mathematics studies, you can surely be in doubt whether there has been any change in the last 100 years.

However, we also know that answers to problems in education-not only mathematics education - can only be offered taking full recognition of the current political, social, and scientific situation. Answers are not and will never be general statements, they always have to be newly evaluated in an on-going process of discussion between different social groups. What is or what might be the impact of Felix Klein's ideas on these current discussion processes?

In the following, we start with some short biographical notes about Felix Klein and give an introduction to his comprehensive program. Then we give an overview of the three strands we offered on the "Thematic Afternoon", each concentrated on 
one important aspect of Felix Klein's work: Functional Thinking, Intuitive Thinking and Visualisation, and Elementary Mathematics from a Higher Standpoint - Conception, Realisation, and Impact on Teacher Education.

\section{Felix Klein: Biographical Notes and His Comprehensive Program}

\section{The Starting Point}

Having been a full professor at the University of Erlangen (1872), the Technical University in Munich (1875), and the University of Leipzig (1880), Felix Klein (1849-1925) joined the University of Göttingen in 1886. He had gained international recognition with his significant achievements in the fields of geometry, algebra, and the theory of functions. On this basis, he was able to create a centre for mathematical and scientific research in Göttingen (Tobies, 2002). Felix Klein was far ahead of his time in supporting all avenues of mathematics, its applications, and mathematical pedagogy. He organised that the establishment of new lectures, professorships, institutes, and curricula went hand in hand with the creation of new examination requirements for prospective secondary school teachers.

Klein was 16 years old when he passed his German Abitur examination, 19 when he completed his doctorate, and 21 when he qualified as university lecturer and he was appointed full professor at the age of 23.

Right from the start, Klein also wanted to improve instruction at secondary schools, because all mathematical instruction at German universities was aimed at training future teachers. In letters to foreign mathematicians, for example, to Gaston Darboux (1842-1917), Klein discussed mathematical problems and teaching questions as early as the 1870s. Darboux arranged for the first translation of a paper by Klein: his famous article on non-Euclidean geometry. In a paper on Darboux, David Hilbert mentioned that it was Darboux who had influenced Klein's educational efforts to a great extent (the central role of the concept of function, for example). Later, Darboux became the director of the French Education Commission, and, in 1914, he chaired the last meeting of the IMUK to take place in Paris before World War I. Klein, as president, could not take part because of health reasons, but had prepared the content of the proceedings (Tobies, 2016).

\section{International Perspectives}

Klein maintained a network of international relations that included, among others, Cayley from Great Britain, Zeuthen from Denmark, Stolz from Austria, Lie from Norway, Cremona from Italy, and Markov from Russia. Mathematicians of the 
older generation encouraged students from France (recommended by Darboux) and other countries to go to Germany and attend Klein's courses. Klein wholeheartedly supported young students in achieving their own research results. Later, many of them would in turn support him with his other projects (especially of the pedagogical sort).

If we look, for example, at Klein's seminar on hypergeometric functions during the winter term of 1893-94, we will not only see the first female students enrolled at the University of Göttingen (they would complete their doctorates under Klein's supervision two years later). We will also see Emanuel Beke (1862-1946), who gave three presentations (January 10, 17, and 24, 1894) in the seminar and would publish two article in "Klein's" journal, Mathematische Annalen (vol. 45 [1894]). Later, in 1906, Beke became the chairman of the Teaching Reform Commission in Hungary, and, in 1908, he endorsed Klein's appointment as the first president of the IMUK/CIEM. Inspired by Klein, Grace Chisholm Young (1868-1944), one of his female doctoral students, wrote a beginner's textbook on geometry that Klein would praise in the second volume of his Elementary Mathematics from a Higher Standpoint. Another participant in the seminar, the American Frederick S. Woods (1864-1950), would earn fame for his mathematical textbooks. Finally, the Italian Gino Fano (1871-1952) not only translated Klein's Erlangen Programme into Italian, he also wrote a paper on his experiences in Göttingen. There he made a special point to mention the interaction between the university world and secondary teachers. Along with other Italian mathematicians - including Gino Loria, Corrado Segre, and Federigo Enriques - Fano propagated Klein's educational ideas, and they organised the translation of some of his other works as well (Coen, 2012, pp. 210-45).

This seminar of 1893-94 was held after Klein's participation in the World's Columbian Exposition and in the Mathematicians Congress of 1893 (Parshall \& Rowe, 1994). At these events, Klein enhanced his international reputation; Charles Hermite (1822-1901) organised the translation of Klein's papers into French and ultimately orchestrated his appointment as a corresponding member of the French Academy (Tobies, 2016). Klein's US trip also caused him to gain more influence in Germany. Friedrich Althoff (1839-1908), an important official at the Prussian Ministry of Culture, came to accept Klein's ideas about the admission of women to university, the improvement of the teacher training, and the promotion of applied mathematics. With Althoff's support, Klein established, in February 1898, the first scientific association for promoting applied physics and mathematics, which brought scientists from the University of Göttingen into contact with 50 influential businessmen from Germany's chemical, electrical, steel, and iron industries. Remarkably enough, the founding members of this association agreed that the improved training of future teachers (in new mathematical fields, applications, and experimental instruction) should be the most important goal. Thus, Klein drafted new examination requirements for prospective secondary school teachers, and these were ratified as early as September 1898. In May 1900, Althoff invited Klein to state his expert opinion in advance of a pedagogical conference in Berlin. This cleared the way for Klein to develop his agenda (Schubring, 1989), which involved contesting opponents on multiple committees and, as member of the Prussian parliament, pushing 
through a reform of mathematical instruction from kindergarten to the university level including the education of girls and young women (Tobies, 1989).

As a sign of his increased international standing, Klein was made a board member of L'Enseignement Mathématique, which was founded in 1899.

This was the first international journal for mathematical instruction, and as such it became the official organ of the first international body, the Internationale Mathematische Unterrichtskommission (IMUK) or Commission Internationale de l'Enseignement Mathématique (CIEM), founded during the IV International Congress of Mathematicians (Rome, April 6-11, 1908), where Klein was electedin absentia - as president. The initiator of this International Commission on Mathematical Instruction (ICMI; this name was adopted in 1954), the American David Eugene Smith (1860-1944), had translated (together with W. W. Beman) Kleins Famous Problems of Elementary Geometry (1897). In 1912, Smith became Vice-President of this commission.

\section{Felix Klein and Mathematics Education}

Klein also stands out for having established the field of mathematical didactics and for having regarded the history of mathematics as a keystone of higher education. He was always keen to underscore the relation between mathematics and culture (Klein, 1912-14). He never pursued the unilateral interests of his subject but rather kept an eye on the latest developments in science and technology. Because of Darwins theory of evolution, for instance, the instruction of biology had been forbidden at Prussian secondary schools since 1882. Together with the biologist Karl Kraepelin (18481915) from Hamburg, Klein overturned this ban in 1904 by initiating a mathematical-scientific instruction committee. Klein was successful because he adopted and respected the interests of other groups and because he promoted mathematicians regardless of their nationality, gender, or religion. To cite one final example of Klein's influence: when Poul Heegaard (1871-1848) took over vice-presidency of IMUK/ICTM in 1932, he publically reminisced about the scientific atmosphere under Klein in the mid-1890s, who had inspired him considerably and had discussed with him the idea that would later form the basis for his doctoral dissertation (O'Connor, Robertson, \& Munkholm, 2010).

It is no wonder that the term Klein's reform was already in wide use during Felix Klein's own lifetime.

In the following, we highlight two main aspects of Felix Klein's work with regard to his influence on mathematics education - organised in two strands at the Thematic Afternoon - and give some information about the new edition of the Elementary Mathematics. 


\title{
Strand A: Functional Thinking
}

If you understand functional thinking as "a way of thinking that is typical for the working with functions," the knowledge about definitions, properties, related concepts, representations, and examples and counter-examples of functions is crucial for the development of functional thinking in mathematics. The understanding of the function concept is a long-standing process, which starts in kindergarten and primary school and can be seen as an open-ended process even in university mathematics. In Strand A we concentrated on two aspects in the frame of the function concept: basic ideas of the function concept and problems with real numbers represented in a number line.

\section{Definitions of Functions}

Consider the following definitions of a function:

\begin{abstract}
A function of a variable quantity is an analytic expression composed in any way whatsoever of the variable quantity and numbers or constant quantities.

The general concept of a function requires that a function of $x$ be defined as a number given for each $x$ and varying gradually with $x$. The value of the function can be given either by an analytic expression or by a condition that provides a means of examining all numbers and choosing one of them, or finally the dependence may exist but remain unknown.

Let $\mathrm{E}$ and $\mathrm{F}$ be two sets, which may or may not be distinct. A relation between a variable element $x$ of $\mathrm{E}$ and a variable element $y$ of $\mathrm{F}$ is called a functional relation in $y$ if, for all $x$ in $\mathrm{E}$, there exists a unique $y$ in $\mathrm{F}$ which is in the given relation with $x$.
\end{abstract}

These definitions exemplify the historical struggle with two key problems in how we think about functions: conceptualizing the function itself as an object, and conceptualizing the domain and range of a function as objects.

\section{Productive Meanings of Functions}

The first presentation at the Thematic Afternoon, by Pat Thompson (Arizona, United States), considered the first problem in the light of US and South Korean teachers' meanings for functions and function notation. He reported on a study of ways that 253 US and 368 South Korean teachers understand the ideas of functions and function notation.

Teachers from both countries were given a 46-item diagnostic instrument (43 items in the Korean version). The instrument focused on variation and co-variation; function properties, modelling, and notation; frames of reference; magnitude and measure; proportionality; rate of change; and structure sense. The focus of this talk was modelling and notation. 
The presentation started with a discussion of how teachers convey meaning. For example, a teacher might have a complex understanding of the rule $-x=x$ in algebra, involving using the properties of operations to derive this rule. But the conveyed meaning in the student's mind might be something much simpler, for example, "If you see more than one minus sign, write it without any minus signs."

The survey found that significantly higher percentages of South Korean teachers (as high as $68 \%$ on some measures) had productive meanings for functions and function notation, whereas the corresponding percentage for US teachers was typically around $30 \%$. Thompson emphasised that it is not that South Korean teachers know more mathematics than US teachers, but rather that a greater percentage of South Korean teachers have mathematical meanings that are potentially productive for student learning.

Thompson suggested that this problem resulted from a vicious cycle, which could also be called the "double discontinuity." Many students leave high school with poorly formed meanings for ideas of the middle and secondary mathematics curriculum. They take mathematics courses in college from instructors who presume, or do not think about whether, students have basic mathematical meanings that they in fact do not have. They therefore apply the same coping mechanisms (e.g., memorisation) in college mathematics that allowed them to succeed in high school mathematics. As a result, they return to high schools to teach ideas they have understood poorly, have rarely revisited, and for which they still have poorlyformed meanings.

He concluded by proposing that professional development focus on teachers' mathematical meanings for the mathematics they teach and on ways that students create mathematical meaning from instruction, suggesting that mathematics departments must play a central role.

\section{Functions and the Number Line}

The second presentation, by Hyman Bass (Michigan, United States), considered the problem of conceptualising the domain of a function through an examination of the number line. A robust understanding of the continuous real number line is a central goal of K-12 education, but the extent to which this is achieved is questionable. Bass argued that the roots of this problem rest to a large extent in the early introduction of numbers in grade 1. He discussed a promising way of approaching this due to a theory by Davydov.

Bass considered the question of a student who, at the end of high school, can meaningfully hear, "Let $\mathrm{f}(x)$ be a function of a real variable $x$." The home of this $x$ is the real number continuum $\mathbf{R}$. How did this $\mathbf{R}$, with its rich algebraic and geometric structure, make itself progressively known to first-grade student Anne, who can be presumed to know little more than simple cardinal counting? There are two possible narratives that can explain this accomplishment.

The construction narrative starts with counting numbers, gradually builds $\mathbf{R}$ by accretion of new numbers (negative integers and fractions), and eventually a "hole 
filling" completion (from $\mathbf{Q}$ to $\mathbf{R}$ ) whose need and nature are often left tacit. A difficulty with this narrative is that fractions appear, conceptually, notationally, and computationally, as a whole new number planet, and their integration into the eventual number continuum that they cohabit with integers and rational numbers is complex and non-intuitive. The construction narrative, characteristic of much of the US curriculum, risks not achieving the final synthesis, an internalised understanding of the real number continuum.

The occupation narrative (promoted by Davydov \& colleagues), in contrast, treats the geometric line as present from the beginning; it is the natural environment for linear measurement. This confers on the geometric line (imagine a thin string, flexible but inelastic) a primordial cognitive status on the same footing as cardinal counting. Measurement is at first of quantities (continuous as well as discrete). Numbers then arise as ratios of two quantities, one taken as a unit against which to measure the other. In this way, once an (oriented) interval on the line is chosen as unit, all intervals acquire, at least conceptually, a numerical measure (or ratio); therefore, the continuum of all real numbers is, at least conceptually, present from the beginning. The progression in the construction narrative above is now replaced by the progressive naming of more and more of these numbers as we locate where they take up residence on the (pre-existing) line.

\section{Strand B: Intuitive Thinking and Visualisation}

In addition to the functional thinking aspect, the second central aspect is surely the idea of Anschauung, a term which is quite hard to translate since it incorporates many facets. It does not stretch only over the geometry part of Klein's books but roots in the basic thinking of Felix Klein on the tasks of the mathematics teachers: They (as Felix Klein once said) will only succeed if they are able to make things "anschaulich erfassbar" ("intuitively comprehensible"). The teacher then has to choose "psychological" ways of presentation, and these are not necessarily the "systematic" ways. For this purpose, a whole bundle of possibilities could and should be used by the teacher: Drawings, pictures, models, experiments, any dynamic representation, as far as it could be realised, etc. This broad range of Felix Klein's central idea of Anschauung brought us to call Strand B "Intuitive Thinking and Visualisation."

\section{Anschauung, Abstraction, and Visualisation}

In the first contribution, Martin Mattheis (Mainz, Germany) displayed the deeper intentions of Felix Klein behind the central aspect Anschauung. In many passages of the books and within the papers on school reform, Felix Klein explains what he means by Anschauung, and some examples can illustrate these ideas: How numbers should be associated with concrete representations, why geometry should be 
connected to a vivid intuition in order to develop a full understanding of abstract concepts, how far functions and especially the infinitesimal calculus rest on graphical representation, and, finally, that mathematical intuition always should precede logical reasoning. Felix Klein also pointed out, however, that one should not cut the higher parts of the concepts, as illustrations are necessary for making mathematics more accessible.

The interplay between abstraction and visualisation was also the starting point of Stefan Halverscheid (Göttingen, Germany) and Oliver Labs (Potsdam and Mainz, Germany), who discussed Felix Klein's mathematical heritage as it can be seen today through 3D models and other tools of visualisation. The possibilities have changed since the time of Felix Klein, but not the basic idea of visualisation. Therefore, we are able to visualise two spaces at the same time on a screen, e.g., making visible the influence of parameters onto the curves, even those of higher degrees. We can draw pictures of functions with two variables, or create dynamic pictures by functions in polar coordinates. Different geometries can be visualised on the computer screen. Nowadays, 3D-printing technologies make it even possible to work with and not just see various $3 \mathrm{D}$ models. These possibilities overcome some inherent difficulties with the historical models in the famous Göttingen collection. Working with 3D-printer models was concretely demonstrated when the audience was given a chance to have their own experiences with tessellation of the 3 -space with given 3D-printer objects. Labs and Halverscheid also provided a small exhibition of $3 \mathrm{D}$ models they created with various printers and showed how they used them in teacher education seminars.

\section{Visualisation and Intuition: Historically and Nowadays}

The second hour of the session was devoted to the impact of Klein's ideas on visualisation and intuition into the modern teaching of mathematics and the realisation of his ideas in classrooms of various levels. Flavia Mammana (Catania, Italy) detected the modernity of the Merano Syllabus for teaching geometry in Grades 10 and 11. Today, an intuitive approach to geometry is facilitated by the use of information technology. However, the central issue of the development from intuition to the concepts still remains. An example how one can use dynamic geometry software to develop concepts showed especially the transitions from 2D to 3D geometry while "seeing" quadrilaterals and/or tetrahedra in certain figures.

For an introductory linear algebra course, Chris Rasmussen (San Diego, United States) invented some visualisation and intuition ideas. Compatible with Klein's views, he presented an instructional sequence that supports students' reinvention of the concepts of span, linear dependence, and linear independence. The approach, labeled as the "Magic Carpet Ride," focuses on vectors, their algebraic and geometric representations in 2 and 3 dimensions, and their properties as sets. Student solutions showed how the creation of formal definitions can proceed from intuition. 
Felix Klein was not alone in creating innovative, e.g., visualisation-oriented, teaching ideas in his time. Other contributors to that field, sometimes with explicit reference to Felix Klein, also played a role. Their work has still influence on the teaching today. In her seminars for prospective teachers, Ysette Weiss-Pidstrygach (Mainz, Germany) used classroom models that Peter Treutlein created with the intention of helping students grasp mathematics. The spirit of Felix Klein in using models for teaching was already being carried on from university to school by Peter Treutlein, a teacher and school headmaster, before the First World War. As Klein also did, he attempted to transform visual perception into logical concepts. Today, his models offer a rich variety of possibilities to relate historical, mathematical, and pedagogical aspects in mathematics teacher education. Examples stretched from paper folding to mathematical experiments.

There were still other figures on the scene, as Sebastian Kitz (Wuppertal, Germany) noted. However, he concentrated on the mathematical animated films that Gymnasium teacher Ludwig Münch used as teaching materials, which have been partly reconstructed in the last years. Produced around 1910, they can be seen as a precursor of modern dynamic geometry environments. Film clips were shown on the Apollonian problem in elementary geometry, the transition of the conic sections into one another, the circle of curvature rolling along a curve and tracking the centre, and planetary motion by Ptolemy and Copernicus. Again, we see that the technological progress of that time could become fruitful in transforming Felix Klein's ideas into realisation. These old mathematical animated films give a good impression of that process.

\section{Strand C: Elementary Mathematics from a Higher Standpoint-Conception, Realisation, and Impact on Teacher Education}

Strand C was concerned with the three volumes of Elementary Mathematics from a Higher Standpoint: their conception, realisation, and impact on teacher education. These lecture notes from the early 20th century were a seminal contribution by Klein to mathematics teacher education, presenting for the first time a methodological orientation for teacher education, not just a content-oriented course. They constituted a model for many later approaches. Strand C intended to assess the importance of this conception of mathematics teacher education, discussed its international impact and reflected about its impact on present-day teacher education.

\section{The Starting Point: Hand-Written Notes}

In a short overview, Gert Schubring (Bielefeld, Germany) showed the transformation from lithography to e-book publication of the three volumes of Klein's 
Elementary Mathematics from a Higher Standpoint. The volumes originated from a two-semester lecture course, first given in 1907-08 to 1908-09. They were published in the form of a Nachschrift of notes taken by experienced students and revised by the professor. This form had become established by students of Weierstraß, who thus enabled that Weierstraß' novel conceptions of analysis, which he did not publish himself, could be disseminated. In Klein's manner of adaptation, a decisively greater number of copies could be disseminated: they were poly-copied by lithography and distributed by the publisher Teubner in Commission: This means that the text was not typeset, but handwritten-fortunately not in the nowadays unusual Sütterlin script. Right at the beginning, on the second page of the first volume, one can find the famous quote about double discontinuity.

Volume II on geometry was distributed in 1909 in the same manner.

What became later, in the general revision for typeset printing, the third volume, had originally, in 1901, been a separate lecture course, on application of differential and integral calculus to geometry: a revision of foundations.

\section{On the Way to a Bestseller}

After the publication of the third, complete, and revised edition of the Elementarmathematik from 1924 to 1928, now in regular book format, the German series became a bestseller, was reprinted many times, and it was also translatedfirst into Spanish, as Matemática elemental desde un punto de vista superior (1927, 1928), and then into English, as Elementary Mathematics from an Advanced Standpoint (1932, 1939).

However, this translation, also many times reprinted, suffers decisive problems:

- The two translators, Earle Raymond Hedrick and Charles Noble, although students of Hilbert and Klein in Göttingen and both later mathematics professors at US universities, apparently never managed their translation to be checked by German native speakers.

- Surely non-Germans had difficulty with the Nachschrift: It is based on oral lectures in a colloquial style where the idioms are not as easy to grasp for a non-German.

- They used the word advanced in the title instead of higher.

- Important parts in Volumes I and II were omitted without comment.

- There are inconsistencies in the mathematical terminology.

- And there were numerous translation errors.

Translations into other languages followed: a four-part Japanese translation (Takai tachiba kara mita shoto: su-gaku, 1959-60 and 1961) and a Russian translation (Elementarnaja matematika s tocki zrenija vyssej, 1987). The most recent translation was into Portuguese: Matemática Elementar de um Ponto de Vista Superior, in five parts (2009-2014). 
All translations so far excluded Volume III and were restricted to Volumes I and II. The only complete translation so far has been the Chinese translation, first published in the People's Republic of China in 1989 and then reprinted in the Republic of China in 1996.

On the occasion of this 13th International Congress on Mathematics Education (ICME-13, Hamburg 2016), the International Commission on Mathematical Instruction (ICMI), together with Springer, has intended to close the gap in the English versions. This was especially a suitable date because Felix Klein was the first president of ICMI (see Section "Felix Klein: Biographical Notes and His Comprehensive Program").

\section{Notes to the Three Volumes}

It is thanks to the initiatives by Gabriele Kaiser and Ferdinando Arzarello that Springer undertook it to publish the first complete translation in modern English of Felix Klein's seminal series of lecture notes - complete meaning that it now also both includes Volume III and integrates the several extended parts of the original of Volumes I and II that had been omitted. ${ }^{1}$

After this overview, the first of the successive two hours of Strand C concerned the content of the three volumes of Elementary Mathematics from a Higher Standpoint.

Gert Schubring analysed Klein's innovative establishment of the word elementary: It was not used in the everyday way meaning "simple," but as the result of the process of elementarisation of complex developments in mathematics, effecting a restructuration of mathematics from new conceived elements. Klein does not prescribe schools to adopt the latest developments in science; rather, he allows them to make proper choices according to criteria of the school system, yielding a certain "hysteresis" behind the recent, not yet elementarised state.

Through examples taken from Volume III, Precision and Approximation Mathematics, Marta Menghini (Rome, Italy) underlined how the relation between applied and pure mathematics was a subject of utmost concern for Klein. For instance, Klein introduces circular inversion starting from physics then creating point sets with particular properties. This example, which was shown using Geogebra, allows illustration of some features of Klein's text: Starting from an intuitive and sometimes practical approach, Klein develops abstract concepts working in rich "mathematical environments," which form the core of an interesting high school mathematics teacher education. Another example concerns the "continuous" transformation of curves, evidencing the invariant properties.

Klein's mathematical, historical, and didactical perspective was illustrated by Henrike Allmendinger (Lucerne, Switzerland), who took a closer look at original

\footnotetext{
${ }^{1}$ Felix Klein, Elementary Mathematics from a Higher Standpoint. 3 volumes. Springer, 2016.
} 
text snippets from the chapter on logarithmic and exponential functions from Klein's Volume I, Arithmetic, Algebra, and Analysis. Klein describes the customary approach to logarithms in school and criticises it, presenting an alternative approach led by the historical development and giving an insight into the logarithms from the standpoint of function theory.

\section{The International Impact}

Jeremy Kilpatrick (Athens, Georgia, United States) commented on the previous part and introduced the second hour, which concerned the international impact of Klein's conceptions, in particular upon teacher education.

Fréderick Gourdeau (Quebéc, Canada) discussed the interplay between disciplinary mathematics and school mathematics in teacher education. The emphasis placed upon content in the mathematical education of teachers is still being questioned today, just as Klein questioned it in his seminal work. Recently, the notion of "mathematical habits of mind" has been at the forefront of some discussions. This was exemplified by recent proposals for curriculum reform in Canada.

The impact of Klein's work for today's mathematics education in Asia was shown by Masami Isoda (Tsukuba, Japan): in particular, a Japanese secondary school textbook from 1943 reveals pertinent influences of Klein and his collaborator Horst von Sanden. The textbook was also used in some parts of East Asia. The basic principle of the textbook is mathematisation, and after WW II this provided the roots of the curriculum principle of "Extension and Integration" in Japan.

Along the same lines, Katalin Gosztonyi (Szeged, Hungary) showed the impact of Klein's work on today's mathematics education in Eastern Europe. She analysed the traces of Klein's influence on Hungarian mathematics education, from his student and colleague Emanuel Beke, through mathematicians at the mid-20th century such as Kalmár and Péter, until the reform of mathematics education led by Tamas Varga in the 1970s. Common aspects of their conception about mathematics are the emphasis on intuition, visuality, organic development, or cultural aspects of mathematics.

\section{Final Remark}

Felix Klein's life shows us that a sensitised person is always necessary in order to recognise problems, think in a visionary manner, and act effectively. The aim of the Thematic Afternoon, "The Legacy of Felix Klein" was to inform, think about, and discuss the meaning of the work and ideas of Felix Klein both currently and in the future. We wanted to show that many ideas that Felix Klein had can be reinterpreted 
in the context of the current situation and give some hints and advice for handling current problems in teacher education and teaching mathematics in high school. In this sense, old ideas stay young, but new people are always necessary to bring these ideas to life.

\section{References}

Coen, S. (Ed.). (2012). Mathematicians in Bologna 1861-1960. Basel: Birkhäuser.

Klein, F. (1893-94). Protocols of his mathematical seminars, Vol. 11. http://www.uni-math.gwdg. de/aufzeichnungen/klein-scans/klein/. Accessed September 21, 2016.

Klein, F. (Ed.). (1912-14). Die Mathematischen Wissenschaften (Die Kultur der Gegenwart, Part III, Abt. 1). Leipzig/Berlin: B.G. Teubner.

O'Connor, J. J., Robertson, E. F., \& Munkholm, H. J. (2010). http://www-groups.des.st-andrews. ac.uk/history/Biographies/Heegaard.html. Accessed September 21, 2016.

Parshall, K. H., \& Rowe, D. E. (1994). In The Emergence of the American Mathematical Research Community 1876-1900: J. J. Sylvester, Felix Klein, and E.H. Moore. USA/UK: American Math. Society/London Math. Society.

Schubring, G. (1989). Pure and applied mathematics in divergent institutional settings in Germany: The role and impact of Felix Klein. In D. E. Rowe \& J. McCleary (Eds.), The history of modern mathematics (Vol. II, pp. 171-220)., Institutions and Applications Boston: Academic Press.

Tobies, R. (1989). Felix Klein als Mitglied des preußischen, Herrenhauses'. Wissenschaftlicher Mathematikunterricht für alle Schüler - auch für Mädchen und Frauen. Der Mathematikunterricht, 35, 4-12.

Tobies, R. (2002). The development of Göttingen into the prussian centre of mathematics and the exact sciences. In N. Rupke (Ed.), Göttingen and the development of the natural sciences (pp. 116-142). Göttingen: Wallstein.

Tobies, R. (2016). Felix Klein und französische Mathematiker. In Th. Krohn \& S. Schöneburg (Ed.), Mathematik von einst für jetzt (pp. 103-132). Hildesheim: Franzbecker.

Open Access Except where otherwise noted, this chapter is licensed under a Creative Commons Attribution 4.0 International License. To view a copy of this license, visit http://creativecommons. org/licenses/by/4.0/.

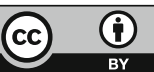

